\title{
Spatial and temporal variations in concentration factors in NW European Seas - secondary use of monitoring data
}

\author{
P.J. Kershaw ${ }^{1}$, C.A. McMahon ${ }^{2}$, A.L. Rudjord ${ }^{3}$, C. Smedley ${ }^{1}$ and K.S. Leonard ${ }^{1}$ \\ ${ }^{1}$ The Centre for Environment, Fisheries \& Aquaculture Science (CEFAS), NR33 OHT Lowestoft, UK \\ ${ }^{2}$ Radiological Protection Institute of Ireland (RPII), Dublin, Ireland \\ ${ }^{3}$ Norwegian Radiological Protection Authority (NRPA)
}

\begin{abstract}
This paper presents new data on concentration factors (CFs: concentration $\mathrm{kg}^{-1}$ biota/concentration $\mathrm{l}^{-1}$ seawater) for several marine species-radionuclide pairs, in three regions: coastal waters of Ireland, eastern Irish Sea and coastal waters of Norway. The CFs were estimated using data from long-term monitoring programmes, obtained for radiological protection purposes. The practical constraints of using such data sources are discussed. CFs were obtained for a range of fin fish, crustaceans, molluscs and brown seaweed, for one or more of the following radionuclides: ${ }^{99} \mathrm{Tc},{ }^{137} \mathrm{Cs}$, ${ }^{239,240} \mathrm{Pu}$ and ${ }^{241} \mathrm{Am}$. In general, there was a relatively high degree of variability in the values obtained, and it was not possible to discern systematic regional or time-dependent differences. However, for two datasets in the eastern Irish Sea $\left({ }^{137} \mathrm{Cs}\right.$ in winkles and crabs) and a number of datasets (137Cs in various species of fish) in the western Irish Sea there was a statistically significant increase in the CF over the monitoring periods. Significant gender differences were found for ${ }^{99} \mathrm{Tc}$ in lobster. The results are compared with current IAEA recommendations and are discussed in relation to the influence of contemporaneous discharges and the possible impact of remobilised radionuclides on bioavailability.
\end{abstract}

\section{INTRODUCTION}

Concentration factors (CFs) are a convenient way of describing the distribution of a radionuclide between an organism and the surrounding water (CFs: concentration $\mathrm{kg}^{-1}$ biota/concentration ${ }^{-1}$ seawater). CFs are used to simulate the behaviour of radionuclides in transport and radiological assessment models, and generic values have been recommended [1,2] for use when site-specific data are unavailable. In the calculation it is assumed that the system is in equilibrium, which in practice may be difficult to demonstrate. For radiological purposes the edible fraction is most often used - the internal concentration can vary considerably between different organs. Despite the general acceptance of CFs as useful tools, there have been relatively few studies in recent years designed to obtain reliable values. This became evident during the revision of the IAEA recommendations [2].

Discharges of radionuclides to the coastal waters of NW Europe have taken place since the early 1950s. This led to the establishment of national programmes to monitor radionuclide concentrations in the main marine compartments, with particular emphasis on the human food chain. Inevitably, the greatest focus was on the Irish Sea and adjoining waters, due to releases from the BNFL Sellafield reprocessing plant on the coast of NW England. The region was subject to relatively high direct discharges in the mid- to late-1970s, leading to significant contamination of the seabed sediments $[3,4]$ and widespread contamination of the waters of the NE Atlantic [5,6]. Throughout this period there were developments in waste treatment and other operations on site, with consequent changes in the discharge pattern. Most recently, in the mid-1990s, the introduction of the Enhanced Actinide Removal Plant (EARP) led to both further reductions (e.g. ${ }^{239,240} \mathrm{Pu}$ ) and significant increases (e.g. ${ }^{99} \mathrm{Tc}$ ) in the quantities 
of radionuclides discharged [7]. However, from the mid-1980s the seabed sediments have become a more important source of ${ }^{137} \mathrm{Cs}$ and plutonium to the water column, and hence to the biota, as a result of remobilisation [8]. It is possible that the bioavailability of remobilised radionuclides will differ from that of direct releases, as a result of chemical and physical changes in the radionuclide associations.

The data used were obtained as part of routine national monitoring programmes in the UK, Ireland and Norway $[9,10,11]$, conducted for radiological assessment and compliance purposes. They represent a variety of sites and species, and in most cases the series were discontinuous. The challenge was to identify the optimum combination of temporal spread, sampling frequency, location, range of species, seawater data and determinands. The data had not been collected for the purpose of calculating CFs and had to be used with caution to ensure we were comparing 'like with like'. Generally the edible fraction was analysed. The aim of the present study was to see whether concentration data collected for radiological monitoring purposes was suitable for deriving CDs, and whether such a study would reveal patterns of regional or temporal variability, which might imply changes in the degree of bioavailability.

\section{RESULTS AND DISCUSSION}

\subsection{Geographical variations}

\subsubsection{Coastal waters of the UK (eastern Irish Sea)}

Despite several tens of thousands of available measurements, from the early 1960s to the present, there were surprisingly few data sets, which provided consistent sampling protocols for the purposes of estimating reliable CFs. The main limitation was on the availability of contemporaneous water measurements. Also, the high concentration gradients near the source, time-varying release rates and mobility of some fish species make it difficult to argue that equilibrium conditions have been achieved. Three species were selected as representative of the main human food-chain pathways: edible crab - crustacean Cancer pagurus; plaice - fin fish Pleuronectes platessa; winkle - mollusc Littorina littorea), with 4 radionuclides which were either of current or historic concern $\left({ }^{99} \mathrm{Tc},{ }^{137} \mathrm{Cs}\right.$, $\left.{ }^{239.240} \mathrm{Pu},{ }^{241} \mathrm{Am}\right)$. Samples were collected from 3 sites and the data were combined: Sellafield, Chapelcross (SW Scotland) and Wylfa (NW Wales). CFs are presented in Table 1, together with the corresponding most recent IAEA recommendations [2] - the latter are non-species-specific, and the explanatory footnotes should be consulted where appropriate.

Table 1. Summary of CFs from coastal waters of the UK.

\begin{tabular}{|c|c|c|c|c|c|c|}
\hline Species & Radionuclide & $\mathbf{n}$ & Mean & Std. dev. & Range & IAEA TRS-422 \\
\hline C. pagurus & ${ }^{99} \mathrm{Tc}$ & 15 & 210 & 98 & $94-410$ & 1000 \\
\hline & ${ }^{137} \mathrm{Cs}$ & 66 & 17 & 12 & $4-57$ & 50 \\
\hline & ${ }^{239,240} \mathrm{Pu}$ & 18 & 113 & 84 & $10-330$ & 200 \\
\hline & ${ }^{241} \mathrm{Am}$ & 18 & $1.4 \times 10^{3}$ & $1.5 \times 10^{3}$ & $3.6 \times 10^{1}-5.3 \times 10^{3}$ & 400 \\
\hline & & & & & & 80 \\
\hline P. platessa & ${ }^{99} \mathrm{Tc}$ & 15 & 78 & 54 & $17-220$ & 200 \\
\hline & ${ }^{137} \mathrm{Cs}$ & 66 & 35 & 21 & $9-160$ & 200 \\
\hline & ${ }^{239,240} \mathrm{Pu}$ & 18 & 2 & 1 & $0.2-4$ & 200 \\
\hline & ${ }^{241} \mathrm{Am}$ & 18 & 8 & 9 & $0.6-28$ & 500 \\
\hline & & & & & & 60 \\
\hline & ${ }^{99} \mathrm{Tc}$ & 16 & $3.1 \times 10^{3}$ & $2.0 \times 10^{3}$ & $1.2 \times 10^{3}-7.7 \times 10^{3}$ & $5-150$ \\
\hline \\
\hline
\end{tabular}




\subsubsection{Coastal waters of Ireland}

Concentration factors were calculated from data obtained in the course of the RPII's routine marine monitoring programme, on the western, southern and eastern Irish coasts, for ${ }^{137} \mathrm{Cs}$ and ${ }^{99} \mathrm{Tc}$ in eight species: brown seaweed - Fucus vesiculosus; mussels - molluscs Mytilus edulis; prawns/nephrops - crustacean Nephrops norvegicus; and five fish species: plaice - P. platessa; cod - Gadus morhua; whiting - Merlangius merlangus; ray - Raja sp.; and mackerel - Scomber scrombus. Sampling took place from 1982 to the present. In most cases, data were available for biota and seawater activity concentrations from identical dates and locations. In some instances (prior to 1998 for ${ }^{99} \mathrm{Tc}$ and prior to 1995 for ${ }^{137} \mathrm{Cs}$ ) only annual averaged data were readily available. In these instances the CFs calculated were assigned a nominal date of July $1^{\text {st }}$ of the year in question. The CFs showed considerable variation but there was no statistically-significant difference between values from the north-east, nearest the source, and those in more remote locations.

Table 2. Summary of CFs from coastal waters of Ireland: a) ${ }^{137} \mathrm{Cs}$, b) ${ }^{99} \mathrm{Tc}$.

a) ${ }^{137} \mathrm{Cs}$ :

\begin{tabular}{|l|c|c|c|c|c|}
\hline \multicolumn{1}{|c|}{ Species } & $\mathbf{n}$ & Mean & Std. dev. & Range & IAEA TRS-422 \\
\hline F. vesiculosus & 172 & 32 & 12 & $7-110$ & 50 \\
\hline M. edulis & 69 & 108 & 61 & $30-360$ & 60 \\
\hline N. norvegicus & 115 & 36 & 19 & $4-142$ & 50 \\
\hline P. platessa & 120 & 48 & 43 & $6-260$ & $100^{*}$ \\
\hline G. morhua & 131 & 86 & 71 & $6-42$ & $100^{*}$ \\
\hline M. merlangus & 132 & 75 & 76 & $3-420$ & $100^{*}$ \\
\hline Raja sp. & 106 & 60 & 49 & $6-297$ & $100^{*}$ \\
\hline S. scrombus & 100 & 30 & 34 & $3-200$ & $100^{*}$ \\
\hline
\end{tabular}

b) ${ }^{99} \mathrm{Tc}:$

\begin{tabular}{|l|c|c|c|c|c|}
\hline \multicolumn{1}{|c|}{ Species } & $\mathbf{n}$ & Mean & Std. dev. & Range & IAEA TRS-422 \\
\hline F. vesiculosus & 58 & $3 \times 10^{4}$ & $2 \times 10^{4}$ & $8 \times 10^{3}-1 \times 10^{5}$ & $3 \times 10^{4}$ \\
\hline M. edulis & 23 & $2 \times 10^{3}$ & $1 \times 10^{3}$ & $4 \times 10^{2}-5 \times 10^{3}$ & $5 \times 10^{2}$ \\
\hline N. norvegicus & 26 & $3 \times 10^{3}$ & $2 \times 10^{3}$ & $2 \times 10^{2}-1 \times 10^{4}$ & $1 \times 10^{3}$ \\
\hline P. platessa & 17 & 18 & 32 & $3-100$ & $80^{*}$ \\
\hline G. morhua & 15 & 10 & 26 & $4-90$ & $80^{*}$ \\
\hline M. merlangus & 17 & 18 & 39 & $2-147$ & $80^{*}$ \\
\hline Raja sp. & 19 & 21 & 17 & $5-58$ & $80^{*}$ \\
\hline S. scrombus & 7 & 15 & 7 & $5-24$ & $80^{*}$ \\
\hline
\end{tabular}

* IAEA TECDOC-422 does not differentiate between different species of fish.

\subsubsection{Coastal waters of Norway}

There have been a several studies of ${ }^{99} \mathrm{Tc}$ uptake in the lobster (Homarus gammarus), as result of the EARP releases and the relatively high bioavailability, which led to relatively high ${ }^{99}$ Tc concentrations. CFs were obtained for a number of biota/sea water samples collected at coastal stations in the southern part of Norway. It was observed that CFs for ${ }^{99} \mathrm{Tc}$ in female lobsters was significantly higher than for males, confirming the findings from the Irish Sea of Swift and Nicholson [12]. In the latter study the 
authors reported considerable variability in concentration, despite trying to control for size, gender and location, and commented on alternative sampling protocols. This is likely to mask more subtle temporal trends in bioavailability.

Table 3. Summary of ${ }^{99}$ Tc CFs for H. gammarus (lobster) from coastal waters of Norway.

\begin{tabular}{|c|c|c|c|c|c|}
\hline Species & $\mathbf{N}$ & Mean & Std. dev. & Range & IAEA TRS-422 \\
\hline $\begin{array}{c}\text { H. gammarus } \\
\text { male }\end{array}$ & 50 & $6 \times 10^{3}$ & $4 \times 10^{3}$ & $2 \times 10^{3}-1 \times 10^{4}$ & $1 \times 10^{3 *}$ \\
\hline $\begin{array}{c}\text { H. gammarus } \\
\text { female }\end{array}$ & 12 & $2 \times 10^{4}$ & $1 \times 10^{4}$ & $1 \times 10^{4}-4 \times 10^{4}$ & $1 \times 10^{3 *}$ \\
\hline
\end{tabular}

\subsubsection{Comparison of regional differences}

There were few datasets, which could be compared. This was largely a reflection of differences in the selection of radionuclides and environmental samples considered of relevance to national monitoring programmes. Comparisons were possible for ${ }^{99} \mathrm{Tc}$ and ${ }^{137} \mathrm{Cs}$ in P. platessa in UK and Irish waters and there was no significant difference. Potentially of more interest would have been a comparison of ${ }^{99} \mathrm{Tc} C \mathrm{CFs}$ in $H$. gammarus, given the high bioavailability and potential dose consequences, but this was prevented by a lack of contemporaneous seawater data from the Irish Sea.

\subsection{Temporal variations}

\subsubsection{Irish Sea}

An attempt was made to compile a long time-series of a range of biota-radionuclide pairs using data from the Irish Sea and UK and Irish coastal waters influenced by the BNFL Sellafield discharges. The objective was to test whether there were significant changes in the observed CFs, which might indicate a change in the degree of bioavailability with time. The relative quantities of radionuclides discharged have varied significantly over the period of the site's operation, with consequent changes in the observed environmental concentrations. Following the considerable decreases in direct discharges in the 1980s, the seabed sediments have been a greater source of caesium and plutonium into the overlying water column due to remobilisation. As a result, the decreases in radionuclide concentrations in seawater and biota have been lower than the decrease in the discharge rate. In addition there have been changes in the operations performed on the site, with the potential to alter the chemical form of the radionuclides in the discharge.

The CFs estimated for the 12 radionuclide-biota pairs from the eastern Irish Sea showed considerable variability. However, there appeared to be a significant correlation for ${ }^{137} \mathrm{Cs}$ in crab and winkles, i.e. the CF increased in the 1960-2000 sampling period (Figure 1). CFs compiled from time-series starting in the early 1980s for the western Irish Sea (Irish coastal waters) were also studied. For nephrops, winkles and Fucus, there were no statistically-significant, time-dependent changes in the biota-radionuclide pairs studied $\left({ }^{137} \mathrm{Cs},{ }^{99} \mathrm{Tc}\right)$. For the 5 commercial fin fish species studied there was an apparent decrease in the CF for ${ }^{137} \mathrm{Cs}$ in all fish species and in cod for ${ }^{99} \mathrm{Tc}$ (Table 4). We do not have an explanation for these apparent changes in Cs bioavailability though the changes observed for ${ }^{137} \mathrm{Cs}$ in fish from Ireland may be due to changed fishing areas, resulting from changes in location of available fish stocks. Under the Irish monitoring programme fish sampling locations are classified by port of landing and not point of fishing. 


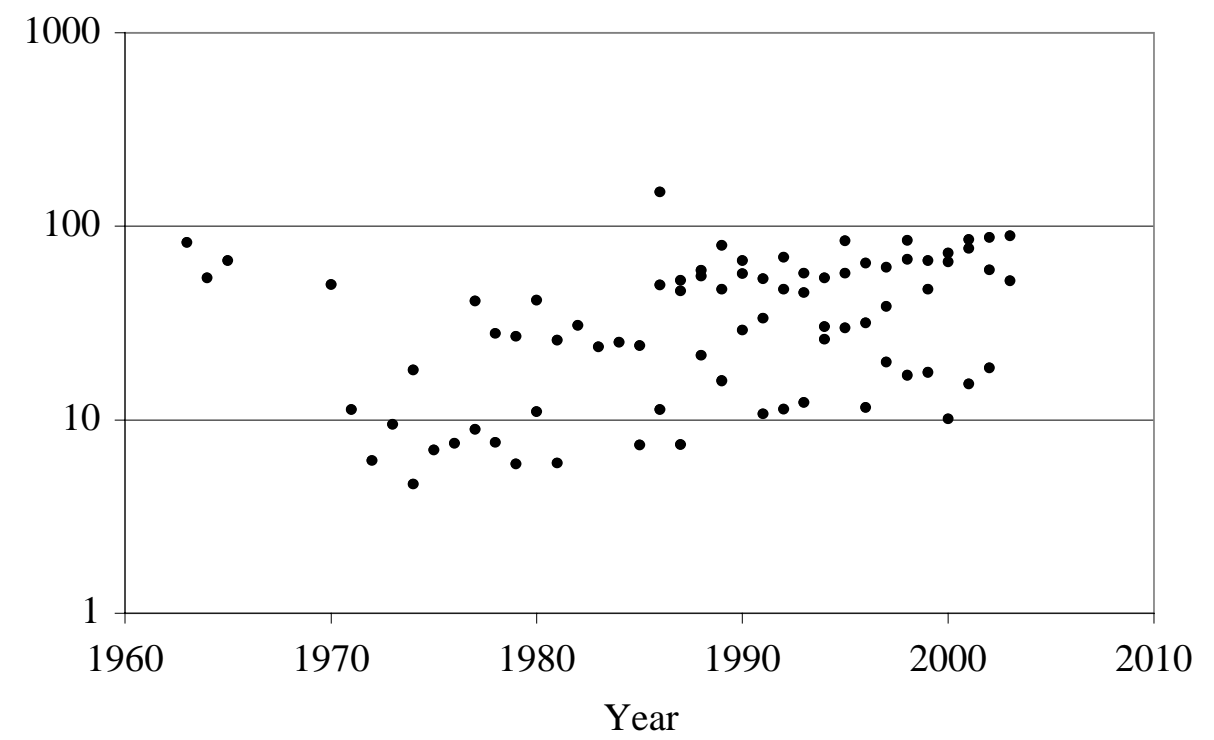

Figure 1. ${ }^{137}$ Cs CF in winkles (L. littorea), 1963-2003, eastern Irish Sea.

Table 4. Correlation coefficients between the year of sampling and estimated CF for a) eastern Irish Sea; b) western Irish Sea.

a) Eastern Irish Sea (Sellafield, Chapelcross SW Scotland, Wylfa Wales)

\begin{tabular}{|c|c|c|c|c|}
\hline Species & Radionuclide & $\mathbf{R}$ & $\mathbf{n}$ & $>95 \%$ probability \\
\hline Crabs & ${ }^{99} \mathrm{Tc}$ & 0.04 & 15 & no \\
\hline \multirow[t]{3}{*}{ C. pagurus } & ${ }^{137} \mathrm{Cs}$ & 0.30 & 66 & yes \\
\hline & ${ }^{239,240} \mathrm{Pu}$ & -0.11 & 18 & no \\
\hline & ${ }^{241} \mathrm{Am}$ & -0.11 & 18 & no \\
\hline Plaice & ${ }^{99} \mathrm{Tc}$ & 0.47 & 15 & no \\
\hline \multirow[t]{3}{*}{$P$. platessa } & ${ }^{137} \mathrm{Cs}$ & 0.21 & 66 & no \\
\hline & ${ }^{239,240} \mathrm{Pu}$ & -0.04 & 18 & no \\
\hline & ${ }^{241} \mathrm{Am}$ & -0.06 & 18 & no \\
\hline Winkles & ${ }^{99} \mathrm{Tc}$ & -0.07 & 16 & no \\
\hline \multirow[t]{3}{*}{ L. littorea } & ${ }^{137} \mathrm{Cs}$ & 0.29 & 79 & yes \\
\hline & ${ }^{239,240} \mathrm{Pu}$ & 0.21 & 26 & no \\
\hline & ${ }^{241} \mathrm{Am}$ & 0.07 & 26 & no \\
\hline
\end{tabular}


b) Western Irish Sea (NE coast of Ireland)

\begin{tabular}{|c|c|c|c|c|}
\hline Species & Radionuclide & $\mathbf{R}$ & $\mathbf{n}$ & $\begin{array}{c}>\mathbf{9 5 \%} \\
\text { probability }\end{array}$ \\
\hline F. vesiculosus & ${ }^{99} \mathrm{Tc}$ & -0.26 & 58 & no \\
\hline & ${ }^{137} \mathrm{Cs}$ & 0.14 & 172 & no \\
\hline Mussels & & & 23 & no \\
\hline M. edulis & ${ }^{99} \mathrm{Tc}$ & 0.20 & 69 & no \\
\hline Dublin bay prawns & ${ }^{137} \mathrm{Cs}$ & -0.02 & 26 & no \\
\hline N. norvegicus & ${ }^{99} \mathrm{Tc}$ & -0.07 & 115 & no \\
\hline Plaice & ${ }^{137} \mathrm{Cs}$ & -0.15 & 17 & no \\
\hline P. platessa & ${ }^{99} \mathrm{Tc}$ & -0.05 & 120 & yes \\
\hline Cod & ${ }^{137} \mathrm{Cs}$ & -0.30 & 15 & yes \\
\hline G. morhua & & & & yes \\
\hline Whiting & ${ }^{99} \mathrm{Tc}$ & -0.73 & & no \\
\hline M. merlangus & ${ }^{137} \mathrm{Cs}$ & -0.26 & 131 & yes \\
\hline Ray & ${ }^{99} \mathrm{Tc}$ & 0.01 & 132 & no \\
\hline raja sp. & ${ }^{137} \mathrm{Cs}$ & -0.45 & 19 & yes \\
\hline Mackerel & & & & 7 \\
\hline S. scrombus & ${ }^{99} \mathrm{Tc}$ & -0.54 & 100 & no \\
\hline
\end{tabular}

\subsubsection{Norwegian coastal waters}

The time-series of ${ }^{99} \mathrm{Tc}$ in lobster from Norwegian waters was rather shorter than for the Irish Sea, instigated as a result of the EARP releases. The mean CF did not vary during the sampling period but the gender difference was persistent and the additional sampling revealed the extent of the variability (Figure 2).

\section{CONCLUSION}

It was possible to make secondary use of radiological monitoring data, of radionuclide concentrations in seawater and biota, to estimate CFs. However, in many cases inconsistencies in sampling protocols over periods of several decades did limit the utility of the data, particularly the lack of

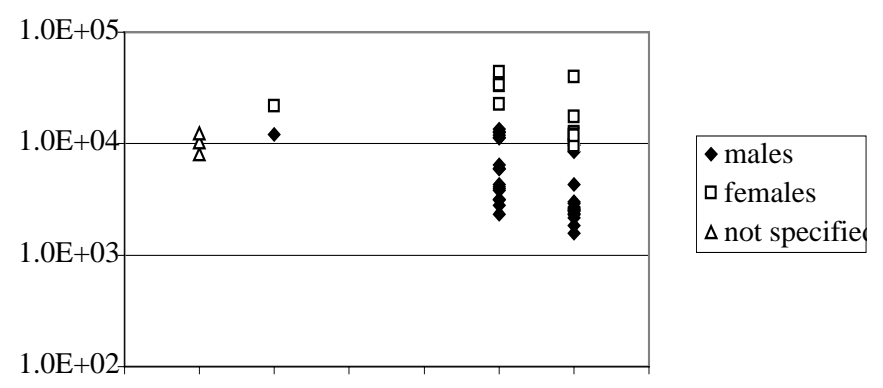

19961997199819992000200120022003

Yeal

Figure 2. ${ }^{99}$ Tc CF in lobster (H. gammarus), 1997-2002, west coast of Norway. 
contemporaneous seawater concentrations. Differences in the priorities of national programmes meant that regional comparisons were very limited. Where they were possible then no differences were observed. There were a few statistically-significant variations in CFs with time, $\left({ }^{137} \mathrm{Cs}\right.$ in winkles and crabs from the eastern Irish Sea and ${ }^{137} \mathrm{Cs}$ in fish landed in the Ireland). For the radionuclides studied the observed CFs were similar to the most recent IAEA recommendations with the following exceptions: ${ }^{99} \mathrm{Tc}-C$. pagarus, $M$ edulis, L. littorea, H. gammarus; ${ }^{239,240} \mathrm{Pu}-P$. platessa; ${ }^{241} \mathrm{Am}-C$. pagarus, $P$. platessa. This demonstrates the continuing importance of obtaining site-specific and species-specific data, particularly in situations leading to significant human exposure.

\section{Acknowledgements}

The authors wish to acknowledge the efforts of many individuals responsible for carrying out the monitoring programmes. We are grateful for the support of the RPII, NRPA and Defra (UK Department for Environment, Food \& Rural Affairs, project C1061). This study was conducted as part of the EU FP5 Remotrans programme (Processes regulating remobilisation, bioavailability and translocation of radionuclides in marine sediments).

\section{References}

[1] IAEA (1985). Sediment $K_{d} s$ and Concentration Factors for radionuclides in the Marine Environment. (Technical Reports Series Number 247. International Atomic Energy Agency. Vienna, Austria).

[2] IAEA, Sediment Distribution Coefficients and Concentration Factors for Biota in the Marine Environment (Technical Reports Series Number 422, International Atomic Energy Agency. Vienna, Austria, 2004) 95pp.

[3] Kershaw P.J., Denoon D.C. and Woodhead D.S., J. Environ. Radioactivity (1999) 44 191-221.

[4] Condren O.M., Mitchell P.I., Leon Vintro L. and Downes A.B., "Plutonium and radiocaesium in western Irish Sea sediments: origin, bioavailability and ultimate fate”, Irish Marine Science Symposium (Royal Irish Academy, Galway, 1995) pp. 567-583.

[5] Kershaw P.J. and Baxter A., Deep-Sea Res. Part II, (1995) 42 (6) 1413-1448.

[6] Brown J.E., Kolstad A.K., Brungot A.L., Lind B., Rudjord A.L., Strand P. and Føyn, L., Mar. Poll. Bull. (1999) 38 (7) 560-571.

[7] Leonard K.S., McCubbin D., Brown J., Bonfield R. and Brooks T., Mar. Poll. Bull. (1997) 34 (8) 628-636.

[8] Hunt G.J. and Kershaw P.J., Remobilisation of artificial radionuclides from the sediments of the Irish Sea. J. Radiol. Protection (1990) 10 (2) 147-151.

[9] RIFE, Radioa ctivity in food and the environment. (RIFE report no. 3. Ministry of Agriculture, Fisheries \& Food (MAFF) and the Scottish Environment Protection Agency (SEPA), London, 1997) 162pp.

[10] Long S., Pollard D., Hayden E., Smith V., Fegan M., Ryan T.P., Dowdall A. and Cunningham J.D., Radioactivity monitoring of the Irish Marine Environment, 1996 and 1997. (Radiological Protection Institute of Ireland, Dublin, 1998).

[11] Brown J.E., Kolstad A.K., Lind B., Rudjord A.L. and Strand P., Technetium-99 contamination in the North Sea and in Norwegian coastal areas 1996 and 1997. (StrålevernRapport 1998:3, Norwegian Radiation Protection Authority, Østerås, 1998) 22pp.

[12] Swift D.J. and Nicholson M.D., J. Environ. Radioactivity 54 (2001) 311-326. 